\title{
Cancer stem cells: The potential of carbon ion beam radiation and new radiosensitizers (Review)
}

\author{
SUNG-JAE BAEK ${ }^{1,2}$, HIDESHI ISHII ${ }^{2,3}$, KEISUKE TAMARI ${ }^{1,2}$, KAZUHIKO HAYASHI $^{1,2}$, NAOHIRO NISHIDA ${ }^{2}$ \\ MASAMITSU KONNO ${ }^{2}$, KOICHI KAWAMOTO ${ }^{2,4}$, JUN KOSEKI $^{3}$, TAKAHITO FUKUSUMI ${ }^{2,5}$, \\ SHINICHIRO HASEGAWA ${ }^{2,4}$, HISATAKA OGAWA ${ }^{2,4}$, ATSUSHI HAMABE ${ }^{2,4}$, MASAAKI MIYO $^{2,4}$, \\ KOZO NOGUCHI $^{2,4}$, YUJI SEO ${ }^{1}$, YUICHIRO DOKI ${ }^{4}$, MASAKI MORI ${ }^{4}$ and KAZUHIKO OGAWA ${ }^{1}$ \\ Departments of ${ }^{1}$ Radiation Oncology, ${ }^{2}$ Frontier Science for Cancer and Chemotherapy, ${ }^{3}$ Cancer Profiling Discovery, \\ ${ }^{4}$ Gastroenterological Surgery and ${ }^{5}$ Otorhinolaryngology and Head and Neck Surgery, Osaka University, \\ Graduate School of Medicine, Suita, Osaka 565-0871, Japan
}

Received June 9, 2015; Accepted July 6, 2015

DOI: 10.3892/or.2015.4236

\begin{abstract}
Cancer stem cells (CSCs) are a small population of cells in cancer with stem-like properties such as cell proliferation, multiple differentiation and tumor initiation capacities. CSCs are therapy-resistant and cause cancer metastasis and recurrence. One key issue in cancer therapy is how to target and eliminate CSCs, in order to cure cancer completely without relapse and metastasis. To target CSCs, many cell surface markers, DNAs and microRNAs are considered as CSC markers. To date, the majority of the reported markers are not very specific to CSCs and are also present in nonCSCs. However, the combination of several markers is quite valuable for identifying and targeting CSCs, although more specific identification methods are needed. While CSCs are considered as critical therapeutic targets, useful treatment methods remain to be established. Epigenetic gene regulators, microRNAs, are associated with tumor initiation and progression. MicroRNAs have been recently considered as promising therapeutic targets, which can alter the therapeutic resistance of CSCs through epigenetic modification. Moreover, carbon ion beam radiotherapy is a promising treatment for CSCs. Evidence indicates that the carbon ion beam is more effective against CSCs than the conventional X-ray beam. Combination therapies of radiosensitizing microRNAs and carbon ion beam
\end{abstract}

Correspondence to: Professor Kazuhiko Ogawa, Department of Radiation Oncology, Osaka University, Graduate School of Medicine, 2-2 (D10) Yamadaoka, Suita, Osaka 565-0871, Japan E-mail:kogawa@radonc.med.osaka-u.ac.jp

Professor Hideshi Ishii, Department of Cancer Profiling Discovery, Osaka University, Graduate School of Medicine, Center of Medical Innovation and Translational Research (0814B), 2-2 Yamadaoka, Suita, Osaka 565-0871, Japan

E-mail: hishii@gesurg.med.osaka-u.ac.jp

Key words: radiosensitizers, cancer stem cells, carbon ion beam radiation, radioresistance, microRNA radiotherapy may be a promising cancer strategy. This review focuses on the identification and treatment resistance of CSCs and the potential of microRNAs as new radiosensitizers and carbon ion beam radiotherapy as a promising therapeutic strategy against CSCs.

\section{Contents}

1. Introduction: Cancer stem cells (CSCs)

2. Methods for identifying CSCs: Biomarkers

3. The resistance mechanisms of CSCs

4. MicroRNAs as radiosensitizers of CSCs

5. Radiotherapy: The potential of carbon ion beam therapy in relation to CSC-targeted treatment

6. Conclusions

\section{Introduction: Cancer stem cells (CSCs)}

Cancer treatments have markedly improved in recent decades. Surgery is considered the main treatment for primary tumors. Yet, surgery has limitations since it can be highly invasive, sometimes causing the loss of function of organs. Improvements in chemoradiotherapy are promising as this modality is less invasive and may preserve organ function. Utilizing a combination of various cancer therapies, such as surgery, radiotherapy, systemic chemotherapy and molecular targeted therapy, locoregional cancer control rates have greatly improved (1). However, relapse and metastasis, which worsen patient outcomes, are of concern. It is important to prevent cancer recurrence and metastasis as the resultant tumors are often more viable and resistant to chemoradiotherapy. The reasons for therapeutic resistant of cancer cells are controversial. However, the cancer stem cell (CSC) theory may provide an accurate explanation.

The CSC theory explains that a small population of cells in a tumor has stem cell properties, such as self-renewal, multiple differentiation and tumor initiation capacities. The idea of CSCs has attacted interest recently, but it was conceptualized 
in 1971 with the discovery of mouse myeloma tumor stem cells (2). When injected into mice, not all leukemia cells but only a small population of leukemia cells initiated tumors, and these tumor-initiating cells were termed CSCs. In humans, CSCs were first discovered in leukemia by Bonnet and Dick in 1997 (3). The recurrence rates of patients with residual tumors after surgery and the rates of distant metastases of patients with circulating cancer cells after successful treatment of the primary tumor were not $100 \%$, although these patients were part of a high-risk group (4-9). These data suggested that not all cancer cells have the potential to cause recurrence and metastasis (10). Recent studies have revealed that CSCs play an important role in maintaining tumor growth (11). Growing evidence suggests that CSCs are resistant to chemoradiotherapy and cause tumor metastasis and recurrence (12). Overall, CSCs are a stem cell-like population in cancer with tumor initiation, self-renewal and multiple differentiation capacities which cause metastasis and recurrence, and it appears that the targeting of CSCs during cancer treatment is a promising strategy for a permanent cancer cure.

In this review, we discuss how the idea of CSCs can be used in future clinical practice. We focus on radiotherapy, particularly the potential of carbon ion beam therapy in relation to CSCs.

\section{Methods for identifying CSCs: Biomarkers}

To date, in order to target CSCs, markers of CSCs have been studied. CSCs have been identified in several types of tumors, and biomarkers have been established, such as those identified by SP assay (13-15): CD44 in breast CSCs (16); and CD133 in hematopoietic CSCs, (17) neural stem cells (18) and colon cancer cells $(19,20)$. These biomarkers are sometimes related with the prognosis of tumors.

CD133 is a major marker of CSCs in various types of cancers, including glioblastoma, rectal cancer and lung cancer (21-24). CD133 is also expressed in differentiated epithelial cells, and some CD133-expressing cancer cells have CSC properties (16-25).

MicroRNA expression in CSCs can also be used for the identification of CSCs. MicroRNAs are endogenous RNAs, which contribute to oncogenic transformation, tumor suppression, and cell differentiation as well as pluripotency (26-28).

Several microRNAs are known as CSC regulators. miR-181 was found to be highly expressed in CSCs in HCC, in embryonic liver tissues, and pluripotent hepatic stem cells in the human liver (29). The expression of miR-130b in $\mathrm{HCC}$ positively regulates $\mathrm{CD} 133^{+} \mathrm{CSC}$ with respect to self-renewal, tumor initiation and chemoresistance properties (30). miR-34a was found to inhibit the growth of CSCs and metastasis in prostate cancer by directly repressing CD44 expression (31). miR-200b negatively regulates CSCs in breast cancer by reducing CSC formation (32). These microRNAs regulate CSCs positively or negatively, and identification of their mechanism of action may make it possible to target or eliminate CSCs specifically.

CSCs can be identified by measuring expression levels of those biomarkers, although these markers are not specific. A combination of these markers may be more useful for identification of CSCs.

\section{The resistance mechanisms of CSCs}

CSCs are a small population present in cancer cells with unique properties: i) self-renewal capability, ii) cell differentiation ability and iii) cancer initiation potential $(33,34)$. These properties of CSCs contribute to chemoradiotherapy resistance and cause tumor recurrence. Enhanced DNA repair capacity and reduced reactive oxygen species (ROS) levels may be responsible for the radioresistance of CSCs (35-38).

Several pathways such as OCT4, WNT, NOTCH, Sonic Hedgehog (SHH), B lymphoma Mo-MLV insertion region 1 homolog (BMI1), and SNAIL1/SLUG are known to be linked to the radiation resistance of CSCs (39). Wang et al reported that inhibition of the NOTCH pathway with $\gamma$-secretase inhibitors sensitized glioma CSCs to radiation (40). Chen et al observed that the survival rate of $\mathrm{CD} 133^{+}$cells was higher than that of CD133- cells after radiation in lung cancer. In the same study, OCT4 knockdown improved the treatment effects of chemoradiotherapy on CD133 ${ }^{+}$cells (41). CD133 is expressed in radiation-resistant CSCs of glioma (36) and colon cancer (42). The DNA repair- and cell cycle-regulating proteins Chk1/ Chk2 have been proven to be related to such resistance. It has also been demonstrated that the inhibition of these kinases improves treatment sensitivity (36). Zhang et al reported that the EMT-inducing transcription factor zinc finger E-box binding homeobox 1 (ZEB1) is a regulator of radiosensitivity and DNA damage response in breast cancer cells (43). In the same study, downregulation of ZEB1 was found to radiosensitize breast cancer cells, indicating that ZEB1-targeting agents could be used as tumor sensitizers.

Recent studies have revealed that certain CSC-related mechanisms are epigenetic. Suvà et al observed that CSCs can be reprogrammed from normal cancer cells in glioblastoma. They also showed that inhibition of the core transcription factors can suppress cancer stem cell properties, and these proteins can be used as therapeutic targets (44). Seguin et al reported that integrin $\beta 3$ expression and the related KRAS-RalB-NF- $\kappa \mathrm{B}$ pathway are both necessary and sufficient for CSC formation and erlotinib resistance. Bortezomib reverses both tumor stemness and erlotinib resistance by inhibiting this pathway (45). These findings suggest that the therapeutic resistance of tumors is related to genetic alterations, and epigenetic removal of CSC properties would enhance the therapeutic sensitivity of tumors.

\section{MicroRNAs as radiosensitizers of CSCs}

MicroRNAs (miRNAs) are small non-coding RNAs that regulate epigenetic gene expression (26). A growing body of evidence suggests that miRNAs are associated with tumor initiation and progression (46-49). Cui et al reported that nanoparticle-delivered miR-200c serves as an effective radiosensitizer of gastric cancer cells and suppresses CSC-like properties (50). CSC-targeted therapies including the miR-200 family tend to damage normal stem cells. Damage to normal cells must be considered in clinical practice, and it is difficult to selectively damage cancer cells while sparing normal cells. By exploiting cellular uptake differences depending on gelatinase levels, Cui et al showed that it possible to spare normal cells via the gelatinase strategy. Gelatinases are overexpressed 


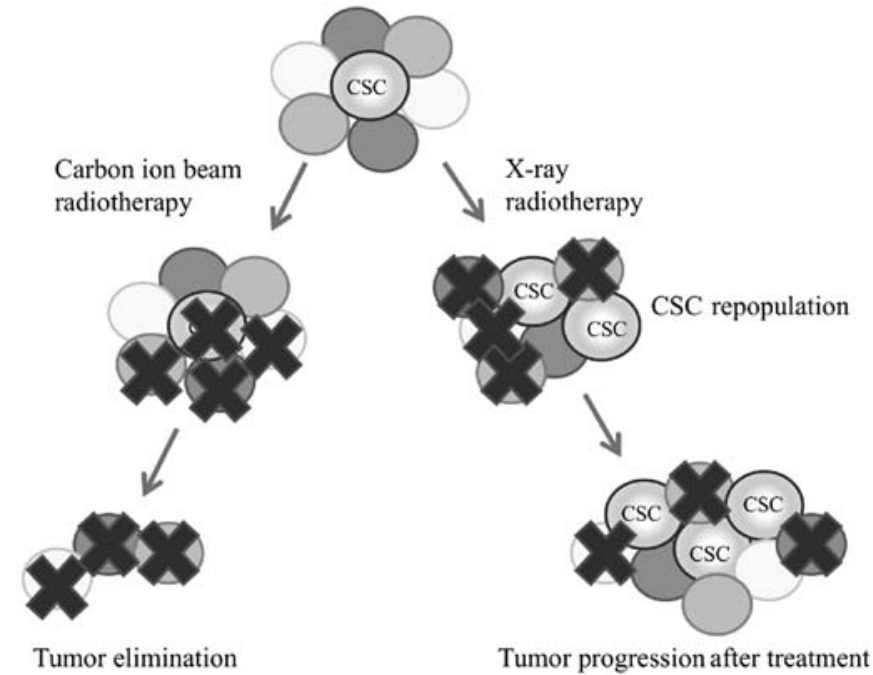

Figure 1. Difference in the biological effects of X-ray and carbon ion beam irradiation. OER of X-ray is between 2.5 and 3.5, which implies that approximately $2 / 3$ of DNA damage is induced indirectly through ROS. Thus, hypoxic cells with low ROS levels are relatively X-ray resistant. OER decreases as LET increases. Carbon ion beam-induced damage is mostly through direct interaction as a high LET beam induces damage regardless of ROS levels. Moreover, a carbon ion beam has strong biological effects; the RBE of a carbon ion beam ranges between 3 and 5, whereas RBE of X-ray is 1.10. OER, oxygen enhanced ratio; ROS, reactive oxygen species; LET, linear energy transfer; RBE, relative biological effect.

in numerous cancers but are undetectable in normal cells (50). Yao et al (52) demonstrated that miR-205 is related with radiosensitivity in breast cancer. Downregulation of miR-205 is observed in radio-resistant cancer cells, and it is highly associated with poor distant relapse-free survival in breast cancer patients. Such findings suggest that miRNAs could be utilized as promising radiosensitizers with minimal side effects, while further in vivo studies and clinical trials are required for clinical utilization.

\section{Radiotherapy: The potential of carbon ion beam therapy in relation to CSC-targeted treatment}

X-ray-induced DNA damage mostly occurs through ROS interaction. CSCs have lower ROS levels and enhanced protection from oxidative damage and therefore exhibit better radiation resistance compared with normal cancer cells $(35,53,54)$. Nevertheless, fractionated radiotherapy may result in the repopulation of CSCs (55). Although normal cancer cells are killed by radiotherapy, radioresistant CSCs can survive and proliferate during such treatment. Thus, an increased proportion of CSCs makes a tumor more aggressive (Figs. 1 and 2).

High-LET heavy ions may be the key to treating the therapeutic resistance of CSCs. Heavy-ion radiotherapy such as carbon ion radiotherapy has higher relative biological effectiveness (RBE), ranging between 3 and 5 (56,57), and therefore is more effective against hypoxic radioresistant cells than conventional X-ray radiotherapy. Carbon ion radiotherapy for malignant tumors has yielded favorable results in several clinical trials (58-63). It was reported that Bcl-2-overexpressing HeLa cells are more resistant to $\gamma$-rays $(0.2 \mathrm{keV} / \mu \mathrm{m})$ and

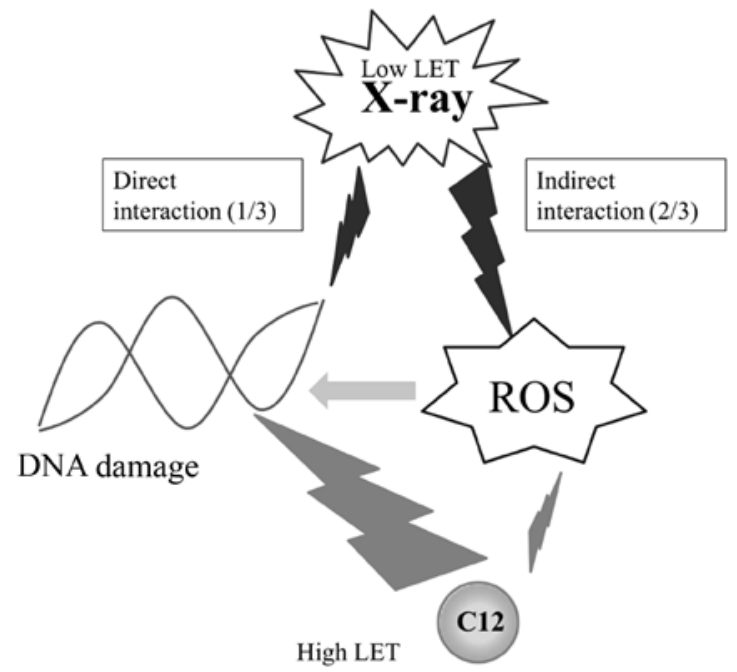

Carbon ion beam

Figure 2. Repopulation of CSCs induced by X-ray radiotherapy and the ability of carbon ion beam radiotherapy in eliminating cancer cells. X-ray-resistant CSCs may survive X-ray radiotherapy while differentiated cancer cells are killed. Thus, the proportion of CSCs at the tumor site increases and causes cancer progression, metastasis and recurrence. Carbon ion beam radiotherapy is more effective against CSCs; therefore, CSC repopulation is less likely to occur. These observations explain the reason why carbon ion beam radiotherapy is a promising modality for cancer elimination. CSCs, cancer stem cells; ROS, reactive oxygen species; LET, linear energy transfer.

helium ions $(16.2 \mathrm{keV} / \mu \mathrm{m})$ than neomycin resistance geneexpressing HeLa cells, whereas heavy ions (76.3-1610 keV/ $\mu \mathrm{m})$ yield similar survival regardless of $\mathrm{Bcl}-2$ overexpression. This implies that heavy-ion radiotherapy may be equally effective against CSCs (64) and that carbon ion beam radiotherapy may not induce CSC repopulation in contrast to $\mathrm{X}$-ray radiotherapy.

Notably, when cancer cells are irradiated by X-rays and a carbon ion beam, genomic expression patterns are changed differentially. Carbon ion beam-specific gene expression patterns may be promising therapeutic targets, which have not been well studied to date.

\section{Conclusions}

CSCs are responsible for tumor recurrence, metastasis and treatment resistance; thus, they are key targets by which to ensure the permanent elimination of cancer cells. Several CSC markers have been recently discovered. Although these markers are not specific, CSCs can be reliably identified using combinations of these markers. Furthermore, specific epigenetic alterations, which are believed to be responsible for the therapeutic resistance of CSCs, are now better understood. These markers and alterations are promising therapeutic targets. By inhibiting the expression of the responsible genes, CSCs can be radiosensitized. Targeting CSCs while sparing non-CSCs is a challenging task as these cell populations exhibit similar expression patterns and biological properties. Recent studies and insights into epigenetic processes and cellular metabolism are providing clues regarding novel promising targeted therapeutic agents that specifically inhibit the growth of CSCs; nanoparticle-delivered miR-200c is a good example. Nevertheless, most studies are currently at the 
in vitro level, and translational research is needed to use these ideas in clinical practice.

Carbon ion beam radiotherapy is a promising method for the elimination of CSCs, with strong effects on CSCs. The tumor control rates of carbon ion beam radiotherapy may be further improved by the use of CSC-targeting drugs such as microRNAs as radiosensitizers. Such combination therapies for carbon ion beam radiotherapy have not yet been adequately researched, and further studies are warranted to establish an optimal combination.

\section{Acknowledgements}

We thank each laboratory staff member for the fruitful discussion and technical assistance. This study was supported in part by a Grant-in-Aid for Scientific Research from the Ministry of Education, Culture, Sports, Science, and Technology; a Grant-in-Aid from the Ministry of Health, Labor and Welfare; a grant from the National Institute of Biomedical Innovation; and a grant from the Osaka University Drug Discovery Funds. Partial support was received from Taiho Pharmaceutical Co., Ltd., Evidence Based Medical Research Center, Chugai Co., Ltd., Yakult Honsha Co., Ltd., Merck Co., Ltd., and the Takeda Science and Medical Research Foundation through the institutional endowments; the funders had no role in study design, data collection and analysis, decision to publish, or preparation of the manuscript.

\section{References}

1. Koch U, Krause M and Baumann M: Cancer stem cells at the crossroads of current cancer therapy failures - radiation oncology perspective. Semin Cancer Biol 20: 116-124, 2010.

2. Park CH, Bergsagel DE and McCulloch EA: Mouse myeloma tumor stem cells: A primary cell culture assay. J Natl Cancer Inst 46: 411-422, 1971.

3. Bonnet $\mathrm{D}$ and Dick J: Human acute myeloid leukemia is organized as a hierarchy that originates from a primitive hematopoietic cell. Nat Med 3: 730-737, 1997.

4. Riethdorf S, Wikman H and Pantel K: Review: Biological relevance of disseminated tumor cells in cancer patients. Int J Cancer 123: 1991-2006, 2008.

5. Fusi A, Collette S, Busse A, Suciu S, Rietz A, Santinami M, Kruit WH, Testori A, Punt CJ, Dalgleish AG, et al: Circulating melanoma cells and distant metastasis-free survival in stage III melanoma patients with or without adjuvant interferon treatment (EORTC 18991 side study). Eur J Cancer 45: 3189-3197, 2009.

6. Swindle P, Eastham JA, Ohori M, Kattan MW, Wheeler T, Maru N, Slawin K and Scardino PT: Do margins matter? The prognostic significance of positive surgical margins in radical prostatectomy specimens. J Urol 179 (Suppl): S47-S51, 2008.

7. Loree TR and Strong EW: Significance of positive margins in oral cavity squamous carcinoma. Am J Surg 160: 410-414, 1990

8. Barrow BJ, Janjan NA, Gutman H, Benjamin RS, Allen P, Romsdahl MM, Ross MI and Pollock RE: Role of radiotherapy in sarcoma of the breast - a retrospective review of the M.D. Anderson experience. Radiother Oncol 52: 173-178, 1999.

9. Alektiar KM, Velasco J, Zelefsky MJ, Woodruff JM, Lewis JJ and Brennan MF: Adjuvant radiotherapy for margin-positive high-grade soft tissue sarcoma of the extremity. Int J Radiat Oncol Biol Phys 48: 1051-1058, 2000.

10. Patel P and Chen EI: Cancer stem cells, tumor dormancy, and metastasis. Front Endocrinol (Lausanne) 3: 125, 2012.

11. Schepers AG, Snippert HJ, Stange DE, van den Born M, van Es JH, van de Wetering $M$ and Clevers H: Lineage tracing reveals $\mathrm{Lgr}^{+}$stem cell activity in mouse intestinal adenomas. Science 337: 730-735, 2012.

12. Singh A and Settleman J: EMT, cancer stem cells and drug resistance: An emerging axis of evil in the war on cancer. Oncogene 29: 4741-4751, 2010.
13. Chiba T, Kita K, Zheng YW, Yokosuka O, Saisho H, Iwama A, Nakauchi $\mathrm{H}$ and Taniguchi H: Side population purified from hepatocellular carcinoma cells harbors cancer stem cell-like properties. Hepatology 44: 240-251, 2006.

14. Haraguchi N, Utsunomiya T, Inoue H, Tanaka F, Mimori $K$, Barnard GF and Mori M: Characterization of a side population of cancer cells from human gastrointestinal system. Stem Cells 24: 506-513, 2006.

15. Ehata S, Johansson E, Katayama R, Koike S, Watanabe A, Hoshino Y, Katsuno Y, Komuro A, Koinuma D, Kano MR, et al: Transforming growth factor- $\beta$ decreases the cancer-initiating cell population within diffuse-type gastric carcinoma cells. Oncogene 30: 1693-1705, 2011.

16. Al-Hajj M, Wicha MS, Benito-Hernandez A, Morrison SJ and Clarke MF: Prospective identification of tumorigenic breast cancer cells. Proc Natl Acad Sci USA 100: 3983-3988, 2003.

17. Yin AH, Miraglia S, Zanjani ED, Almeida-Porada G, Ogawa M, Leary AG, Olweus J, Kearney J and Buck DW: AC133, a novel marker for human hematopoietic stem and progenitor cells. Blood 90: 5002-5012, 1997.

18. Uchida N, Buck DW, He D, Reitsma MJ, Masek M, Phan TV, Tsukamoto AS, Gage FH and Weissman IL: Direct isolation of human central nervous system stem cells. Proc Natl Acad Sci USA 97: 14720-14725, 2000.

19. O'Brien CA, Pollett A, Gallinger S and Dick JE: A human colon cancer cell capable of initiating tumour growth in immunodeficient mice. Nature 445: 106-110, 2007.

20. Ricci-Vitiani L, Lombardi DG, Pilozzi E, Biffoni M, Todaro M, Peschle $\mathrm{C}$ and De Maria R: Identification and expansion of human colon-cancer-initiating cells. Nature 445: 111-115, 2007.

21. Murat A, Migliavacca E, Gorlia T, Lambiv WL, Shay T, Hamou MF, de Tribolet N, Regli L, Wick W, Kouwenhoven MC, et al: Stem cell-related 'self-renewal' signature and high epidermal growth factor receptor expression associated with resistance to concomitant chemoradiotherapy in glioblastoma. $\mathbf{J}$ Clin Oncol 26: 3015-3024, 2008.

22. Tamura K, Aoyagi M, Wakimoto H, Ando N, Nariai T, Yamamoto $\mathrm{M}$ and Ohno K: Accumulation of CD133-positive glioma cells after high-dose irradiation by Gamma Knife surgery plus external beam radiation. J Neurosurg 113: 310-318, 2010.

23. Saigusa S, Tanaka K, Toiyama Y, Yokoe T, Okugawa Y, Kawamoto A, Yasuda H, Morimoto Y, Fujikawa H, Inoue Y, et al: Immunohistochemical features of CD133 expression: Association with resistance to chemoradiotherapy in rectal cancer. Oncol Rep 24: 345-350, 2010.

24. Shien K, Toyooka S, Ichimura K, Soh J, Furukawa M, Maki Y, Muraoka T, Tanaka N, Ueno T, Asano H, et al: Prognostic impact of cancer stem cell-related markers in non-small cell lung cancer patients treated with induction chemoradiotherapy. Lung Cancer 77: 162-167, 2012.

25. Shmelkov SV, Butler JM, Hooper AT, Hormigo A, Kushner J, Milde T, St Clair R, Baljevic M, White I, Jin DK, et al: CD133 expression is not restricted to stem cells, and both $\mathrm{CD} 133^{+}$and CD133 metastatic colon cancer cells initiate tumors. J Clin Invest 118: 2111-2120, 2008.

26. Bartel DP: MicroRNAs: Genomics, biogenesis, mechanism, and function. Cell 116: 281-297, 2004.

27. O'Donnell KA, Wentzel EA, Zeller KI, Dang CV and Mendell JT: c-Myc-regulated microRNAs modulate E2F1 expression. Nature 435: 839-843, 2005.

28. Johnson SM, Grosshans H, Shingara J, Byrom M, Jarvis R, Cheng A, Labourier E, Reinert KL, Brown D and Slack FJ: RAS is regulated by the let-7 microRNA family. Cell 120: 635-647, 2005.

29. Ji J, Yamashita T, Budhu A, Forgues M, Jia HL, Li C, Deng C, Wauthier E, Reid LM, Ye QH, et al: Identification of microRNA-181 by genome-wide screening as a critical player in EpCAM-positive hepatic cancer stem cells. Hepatology 50: 472-480, 2009.

30. Ma S, Tang KH, Chan YP, Lee TK, Kwan PS, Castilho A, Ng I, Man K, Wong N, To KF, et al: miR-130b promotes CD133(+) liver tumor-initiating cell growth and self-renewal via tumor protein 53-induced nuclear protein 1. Cell Stem Cell 7: 694-707, 2010.

31. Liu C, Kelnar K, Liu B, Chen X, Calhoun-Davis T, Li H, Patrawala L, Yan H, Jeter C, Honorio S, et al: The microRNA miR-34a inhibits prostate cancer stem cells and metastasis by directly repressing CD44. Nat Med 17: 211-215, 2011. 
32. Iliopoulos D, Lindahl-Allen M, Polytarchou C, Hirsch HA, Tsichlis PN and Struhl K: Loss of miR-200 inhibition of Suz12 leads to polycomb-mediated repression required for the formation and maintenance of cancer stem cells. Mol Cell 39: 761-772, 2010

33. Sagar J, Chaib B, Sales K, Winslet M and Seifalian A: Role of stem cells in cancer therapy and cancer stem cells: A review. Cancer Cell Int 7: 9, 2007.

34. Bixby S, Kruger GM, Mosher JT, Joseph NM and Morrison SJ Cell-intrinsic differences between stem cells from different regions of the peripheral nervous system regulate the generation of neural diversity. Neuron 35: 643-656, 2002.

35. Diehn M, Cho RW, Lobo NA, Kalisky T, Dorie MJ, Kulp AN, Qian D, Lam JS, Ailles LE, Wong M, et al: Association of reactive oxygen species levels and radioresistance in cancer stem cells. Nature 458: 780-783, 2009.

36. Bao S, Wu Q, McLendon RE, Hao Y, Shi Q, Hjelmeland AB, Dewhirst MW, Bigner DD and Rich JN: Glioma stem cells promote radioresistance by preferential activation of the DNA damage response. Nature 444: 756-760, 2006.

37. Phillips TM,McBrideWHandPajonkF: The response of CD24//low/ $\mathrm{CD} 44^{+}$breast cancer-initiating cells to radiation. J Natl Cancer Inst 98: 1777-1785, 2006.

38. Chiou SH, Kao CL, Chen YW, Chien CS, Hung SC, Lo JF, Chen YJ, Ku HH, Hsu MT and Wong TT: Identification of CD133-positive radioresistant cells in atypical teratoid/rhabdoid tumor. PLoS One 3: e2090, 2008.

39. Ogawa K, Yoshioka Y, Isohashi F, Seo Y, Yoshida K and Yamazaki H: Radiotherapy targeting cancer stem cells: Current views and future perspectives. Anticancer Res 33: 747-754, 2013.

40. Wang J, Wakeman TP, Lathia JD, Hjelmeland AB, Wang XF, White RR, Rich JN and Sullenger BA: Notch promotes radioresistance of glioma stem cells. Stem Cells 28: 17-28, 2010.

41. Chen YC, Hsu HS, Chen YW, Tsai TH, How CK, Wang CY, Hung SC, Chang YL, Tsai ML, Lee YY, et al: Oct-4 expression maintained cancer stem-like properties in lung cancer-derived CD133-positive cells. PLoS One 3: e2637, 2008.

42. Ieta K, Tanaka F, Haraguchi N, Kita Y, Sakashita H, Mimori K Matsumoto T, Inoue H, Kuwano $\mathrm{H}$ and Mori M: Biological and genetic characteristics of tumor-initiating cells in colon cancer. Ann Surg Oncol 15: 638-648, 2008.

43. Zhang P, Wei Y, Wang L, Debeb BG, Yuan Y, Zhang J, Yuan J, Wang M, Chen D, Sun Y, et al: ATM-mediated stabilization of ZEB1 promotes DNA damage response and radioresistance through CHK1. Nat Cell Biol 16: 864-875, 2014.

44. Suvà ML, Rheinbay E, Gillespie SM, Patel AP, Wakimoto H, Rabkin SD, Riggi N, Chi AS, Cahill DP, Nahed BV, et al: Reconstructing and reprogramming the tumor-propagating potential of glioblastoma stem-like cells. Cell 157: 580-594, 2014.

45. Seguin L, Kato S, Franovic A, Camargo MF, Lesperance J, Elliott KC, Yebra M, Mielgo A, Lowy AM, Husain H, et al: An integrin $\beta_{3}$-KRAS-RalB complex drives tumour stemness and resistance to EGFR inhibition. Nat Cell Biol 16: 457-468, 2014.

46. Calin GA, Dumitru CD, Shimizu M, Bichi R, Zupo S, Noch E, Aldler H, Rattan S, Keating M, Rai K, et al: Frequent deletions and down-regulation of micro-RNA genes miR15 and miR16 at $13 q 14$ in chronic lymphocytic leukemia. Proc Natl Acad Sci USA 99: 15524-15529, 2002

47. He L, Thomson JM, Hemann MT, Hernando-Monge E, Mu D, Goodson S, Powers S, Cordon-Cardo C, Lowe SW, Hannon GJ, et al: A microRNA polycistron as a potential human oncogene. Nature 435: 828-833, 2005.

48. Ma L, Teruya-Feldstein J and Weinberg RA: Tumour invasion and metastasis initiated by microRNA-10b in breast cancer. Nature 449: 682-688, 2007.
49. Iorio MV and Croce CM: MicroRNAs in cancer: Small molecules with a huge impact. J Clin Oncol 27: 5848-5856, 2009.

50. Cui FB, Liu Q, Li RT, Shen J, Wu PY, Yu LX, Hu WJ, Wu FL, Jiang CP, Yue GF, et al: Enhancement of radiotherapy efficacy by miR-200c-loaded gelatinase-stimuli PEG-Pep-PCL nanoparticles in gastric cancer cells. Int J Nanomed 13: 2345-2358, 2014.

51. Gupta GP and Massagué J: Cancer metastasis: Building a framework. Cell 127: 679-695, 2006.

52. Yao HP, Zhou YQ, Zhang R and Wang MH: MSP-RON signalling in cancer: Pathogenesis and therapeutic potential. Nat Rev Cancer 13: 466-481, 2013.

53. Blazek ER, Foutch JL and Maki G: Daoy medulloblastoma cells that express CD133 are radioresistant relative to $\mathrm{CD} 133^{-}$cells, and the $\mathrm{CD}_{133^{+}}$sector is enlarged by hypoxia. Int $\mathrm{J}$ Radiat Oncol Biol Phys 67: 1-5, 2007.

54. Kim HM, Haraguchi N, Ishii H, Ohkuma M, Okano M, Mimori K, Eguchi H, Yamamoto H, Nagano H, Sekimoto M, et al: Increased CD13 expression reduces reactive oxygen species, promoting survival of liver cancer stem cells via an epithelial-mesenchymal transition-like phenomenon. Ann Surg Oncol 19 (Suppl 3): S539-S548, 2012.

55. Kim JJ and Tannock IF: Repopulation of cancer cells during therapy: An important cause of treatment failure. Nat Rev Cancer 5: 516-525, 2005.

56. Grün R, Friedrich T, Elsässer T, Krämer M, Zink K, Karger CP, Durante M, Engenhart-Cabillic R and Scholz M: Impact of enhancements in the local effect model (LEM) on the predicted RBE-weighted target dose distribution in carbon ion therapy. Phys Med Biol 57: 7261-7274, 2012.

57. Durante $M$ and Loeffler JS: Charged particles in radiation oncology. Nat Rev Clin Oncol 7: 37-43, 2010.

58. Jingu K, Tsujii H, Mizoe JE, Hasegawa A, Bessho H, Takagi R, Morikawa T, Tonogi M, Tsuji H, Kamada T, et al; Organizing Committee for the Working Group for Head-and-Neck Cancer: Carbon ion radiation therapy improves the prognosis of unresectable adult bone and soft-tissue sarcoma of the head and neck. Int J Radiat Oncol Biol Phys 82: 2125-2131, 2012.

59. Ishikawa H, Tsuji H, Kamada T, Akakura K, Suzuki H, Shimazaki J and Tsujii H; Working Group for Genitourinary Tumors: Carbon-ion radiation therapy for prostate cancer. Int $\mathbf{J}$ Urol 19: 296-305, 2012.

60. Kato S, Ohno T, Tsujii H, Nakano T, Mizoe JE, Kamada T, Miyamoto T, Tsuji H, Kato H, Yamada S, et al; Working Group of the Gynecological Tumor: Dose escalation study of carbon ion radiotherapy for locally advanced carcinoma of the uterine cervix. Int J Radiat Oncol Biol Phys 65: 388-397, 2006.

61. Kato H, Tsujii H, Miyamoto T, Mizoe JE, Kamada T, Tsuji H, Yamada S, Kandatsu S, Yoshikawa K, Obata T, et al; Liver Cancer Working Group: Results of the first prospective study of carbon ion radiotherapy for hepatocellular carcinoma with liver cirrhosis. Int J Radiat Oncol Biol Phys 59: 1468-1476, 2004.

62. Miyamoto T, Baba M, Sugane T, Nakajima M, Yashiro T, Kagei K, Hirasawa N, Sugawara T, Yamamoto N, Koto M, et al; Working Group for Lung Cancer: Carbon ion radiotherapy for stage I non-small cell lung cancer using a regimen of four fractions during 1 week. J Thorac Oncol 2: 916-926, 2007.

63. Mizoe JE, Hasegawa A, Jingu K, Takagi R, Bessyo $H$, Morikawa T, Tonoki M, Tsuji H, Kamada T, Tsujii $\mathrm{H}$, et al; Organizing Committee for the Working Group for Head Neck Cancer: Results of carbon ion radiotherapy for head and neck cancer. Radiother Oncol 103: 32-37, 2012.

64. Nakano T, Suzuki Y, Ohno T, Kato S, Suzuki M, Morita S, Sato S, Oka K and Tsujii H: Carbon beam therapy overcomes the radiation resistance of uterine cervical cancer originating from hypoxia. Clin Cancer Res 12: 2185-2190, 2006. 